\title{
Effect of Liner Cone Angle, Liner Thickness and Wave Shaper in Large Caliber Shaped Charge Warheads
}

\author{
Mukesh Kumar*, Yashpal Singh, Pravendra Kumar \\ Scientist, Terminal Ballistics Research Laboratory, Sector -30 Chandigarh-160030 \\ *E mail:mukesh98519@gmail.com
}

Keywords: Shaped Charge Warheads, Hydrocode, Wave Shaper, Autodyn 2D

\begin{abstract}
Shaped charge warheads are being utilized in defence applications against a wide variety of targets provided by armour, RCC and soil cover. Shaped charge warhead focus the explosive energy by the use of a cavity lined with metal normally called a liner. The concentration of energy along the axis of the warhead acts as force multiplier and hence lighter warheads are possible for deeper penetration. Performance of the shaped charge warhead is function of jet tip velocity, jet length and break up time (BUT). These performance parameters are greatly influenced by liner geometry, liner thickness and liner cone angle and selection of explosive. In this paper, simulations using AUTODYN numerical hydrocode were carried out to study the effect of liner geometry (Tulip vs conical), liner cone angle $\left(50^{\circ}, 60^{\circ}, 70^{\circ}, 80^{\circ}\right)$ and liner thickness $(4 \mathrm{~mm}, 6 \mathrm{~mm}, 8 \mathrm{~mm}, 10 \mathrm{~mm}$ and $12 \mathrm{~mm}$ ) on large caliber shaped charge warheads. Numerical simulations were also done to study the effect of wave shaper in shaped charge warhead. A shaped charge warhead of dia.340mm has been designed by using AUTODYN numerical hydrocode. OFE Copper (ASTM B152 C10100) is used as liner material. A wave shaper of dia.210mm and nylon material was used in shaped charge warhead. An Eulerian approach was used for the liner, casing, wave shaper and explosive parts. A single point initiation in the centre of the rear end of warhead was chosen. The numerical simulation results showed that the jet- tip velocity decreases in between $15-20 \%$ of liner position with increasing the cone angle when the other parameters are the same. For the cone angle $60^{\circ}$, jet tip-velocity decreases as liner thickness is increased from $4 \mathrm{~mm}\left(\mathrm{~V}_{\mathrm{j} \text {-tip }}: 8.14 \mathrm{~km} / \mathrm{s}\right)$ to $12 \mathrm{~mm}\left(\mathrm{~V}_{\mathrm{j} \text {-tip }}\right.$ : $6.7 \mathrm{~km} / \mathrm{s}$ ). It was also realized that in case of wave shaper warhead there is more than $15 \%$ increase in jet tip velocity and $10 \%$ increase in jet length in comparison to without wave shaper warhead due to increase in collapse velocity of liner elements. The slug velocity is $1.22 \mathrm{~km} / \mathrm{s}$ in case of with wave shaper warhead whereas it was $1.05 \mathrm{~km} / \mathrm{s}$ in without wave shaper. It means that a decision for the selection of liner geometry and dimensions of a shaped charge penetrator should be done according to target, required desired effect on target, permissible weight and available space for the warhead.
\end{abstract}

\section{Introduction}

The high-speed jet resulting from the detonation of shaped charge is used to penetrate and demolish hardened targets in military and commercial area. Particularly, the shaped charge is mainly used to penerate armoured vehicles such as tanks, to demolish bunkers, fuel tanks and bridges constructions. In addition, warheads designed by using the shaped charge principle are also used against submarines targets. In the industry, shaped charge are generally used in geophysical areas e.g. petroleum research, mining, steel industry and well bore penetration, underwater trenching and demolition. Two- and Three-dimensional numerical simulation of shaped charges play an important role in testing and designing of shaped charges. In recent studies,computer programs based on Eulerian and Lagrangian calcultions such as "Hydrocode"are utilized to design shaped charges warheads. Generally, the programs provide a good tool facility to analyze problems under very large material deformations.

(c) (1) Content from this work may be used under the terms of the Creative Commons Attribution 3.0 license. Any further distribution of this work must maintain attribution to the author(s) and the title of the work, journal citation and DOI. Published under license by Materials Research Forum LLC. 
In this paper, a shaped charge warhead of dia.340mm has been designed using AUTODYN numerical hydrocode simulation using 2D-axisymmetric model. The effect of liner geometry, liner cone angle, explosive and liner thickness were studied on large caliber shaped charge warhead. Jet characteristics such as jet tip velocity, slug velocity, BUT and jet length of shaped charge warheads with wave shaper and without wave shaper were also calculated. OFE Copper (ASTM B152 C10100) is used as liner whereas Comp B is used as explosive. A wave shaper of dia.210mm with nylon material is used in shaped charge warhead.

\section{Description of shaped charges}

The shaped charge principles were first used in developing weapons by Germans during World War-I. At present, the geometry of the modern shaped charges consists of a cylinder of explosive with a hollow cavity in one end and a detonator at the other end. The hollow cavity is usually lined with a thin layer of metal, glass and ceramics. The cross section of a typical shaped charge is given in Fig.1.

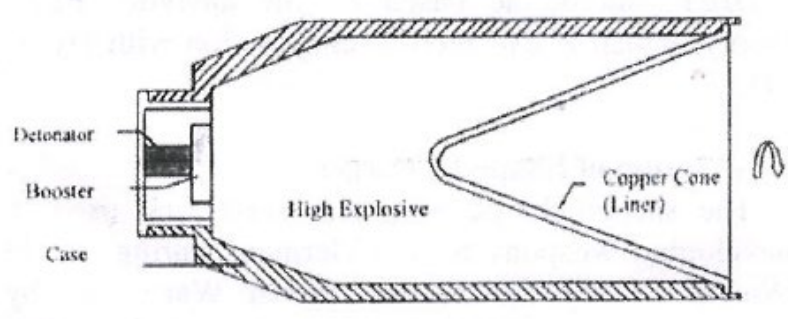

Fig.1- Cross-section of a typical shaped charge

The ignition of detonator causes a shock wave, which detonates the high explosive. The detonation waves which propagate spherically into the explosive moves at a very large velocity, around $5-10 \mathrm{~km} / \mathrm{s}$. When the detonation wave reaches the conical liner surface, a conical liner is accelearted from apex to the base on the cylinder axis under the high detonation pressure,collapisng the liner . As the conical liner material is loaded with high energy, it collapses on the axis, which generates a hypervelocity jet. It is commonly known that the inner liner material on the cavity side forms the jet-tip which has an extremely high velocity, while the outer of the liner material which is in the contact with high explosive forms a jet tail called "slug" which is massive but has slow velocity.The front of the jet (jet-tip) has a velocity range $5-10 \mathrm{~km} / \mathrm{s}$, while the back of the jet (jettail) has a velocity range of $0.5-1.0 \mathrm{~km} / \mathrm{s}$. The conical liner collapse and jet formation process in a shaped charge after initiation of detonation is shown in Fig.2

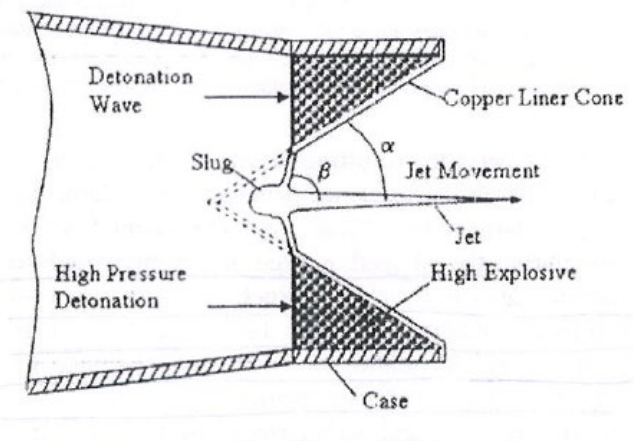

Fig.2 - Liner collapse and jet formation process 


\section{Numerical simulation}

3.1 Finite element analaysis:

In this section, the finite-element model will be described. The following section contains the analysis of the jet formation.

3.2 Simulation tools used:

ANSYS AUTODYN 2D/3D non-linear hydrocode was used. It is an explicit numerical analysis code, where the equations of mass, momentum and energy conservation coupled with materials descriptions are solved. Alternative numerical processors are available and can be selectively used to model different regions of a problem. The currently available processors include Lagrange, Euler, Euler FCT, ALE (Arbitrary Lagrange Euler) and SPH (Smooth particle Hydrodynamics), shell which make them suited to a wide range of non-linear dynamics problem. The codes are particularly suited to the modeling of impact, penetration, blast and explosive events.

3.3 Structure of shaped charge :

On the basis of theoretical analyis,a shaped charge of dia.340mm and warhead length $450 \mathrm{~mm}$ has been designed having length/diameter ratio 1.3 by AUTODYN2D software. Liner is having a thickness of $4 \mathrm{~mm}$ with a cone angle of $60^{\circ}$.OFE Copper (ASTM B152 C10100) is used as liner whereas Comp B is used as explosive. Comp-B which is a secondary high explosive type is selected as high explosive material in the simulations. It is a mixture of $60 \% \mathrm{RDX}$ and $40 \% \mathrm{TNT}$ by weight.

(A) Effect of Wave shaper in large caliber shaped charge warhead:

Numerical simulations were carried out to study the effect of wave shaper in shaped charge warhead. Jet characterisctics such as jet tip velocity,slug velocity and jet length of shaped charge warheads with wave shaper and without wave shaper were calculated at time $t=350 \mu \mathrm{s}$.

(i) Numerical simulation results without wave shaper shaped charge warhead:

Jet-tip velocity and slug velocity with and without wave shaper in large caliber shaped charge warhead are shown in Table: 1.

Table 1: Jet- tip velocity with and without wave shaper

\begin{tabular}{|c|c|c|c|}
\hline S.No. & Liner Thickness & $\begin{array}{l}\text { Without wave shaper } \\
\text { Jet- tip velocity(km/s) }\end{array}$ & $\begin{array}{l}\text { With wave shaper } \\
\text { Jet tip velocity(km/s) }\end{array}$ \\
\hline 1. & $4 \mathrm{~mm}$ & 6.08 & 8.14 \\
\hline 2. & $6 \mathrm{~mm}$ & 5.88 & 7.60 \\
\hline 3. & $8 \mathrm{~mm}$ & 5.59 & 7.20 \\
\hline 4. & $10 \mathrm{~mm}$ & 5.02 & 6.95 \\
\hline
\end{tabular}




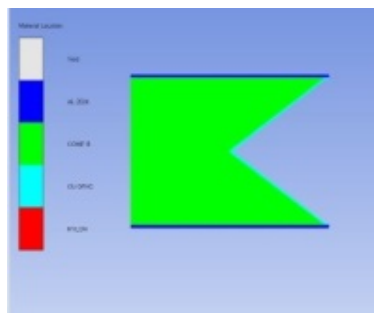

$\mathrm{T}=0 \mu \mathrm{s}$

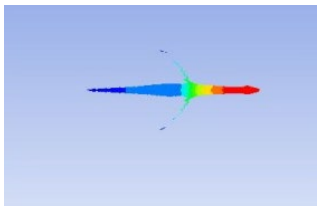

$\mathrm{T}=160 \mu \mathrm{s}$

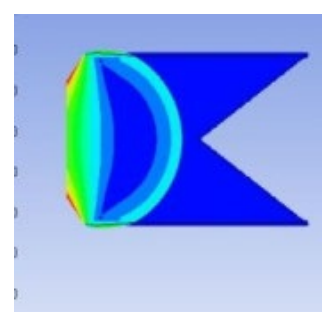

$\mathrm{T}=29 \mu \mathrm{s}$

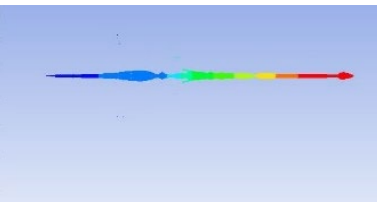

$\mathrm{T}=289 \mu \mathrm{s}$

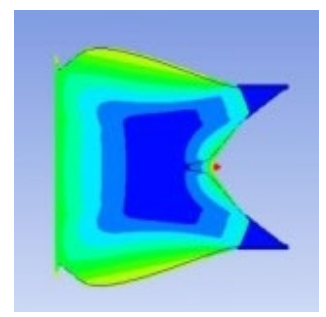

$\mathrm{T}=57 \mu \mathrm{s}$

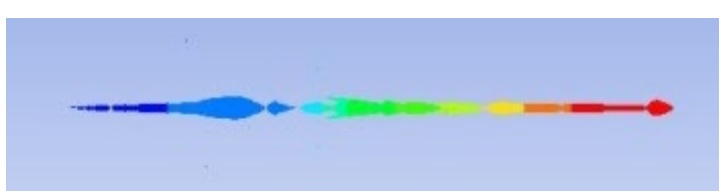

$\mathrm{T}=350 \mu \mathrm{s}$

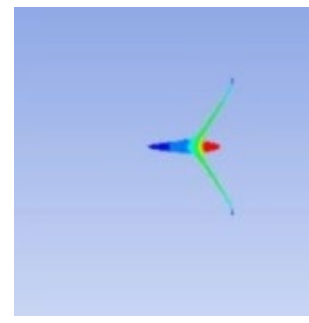

$\mathrm{T}=84 \mu \mathrm{s}$

Fig. 5 Formation of jet without wave shaper at different time steps

(ii). Numerical simulation results with wave shaper shaped charge warhead:

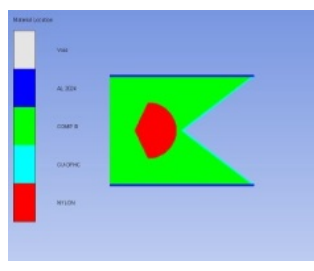

$\mathrm{T}=0 \mu \mathrm{s}$

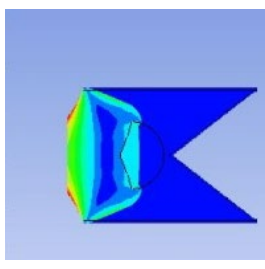

$\mathrm{T}=27 \mu \mathrm{s}$

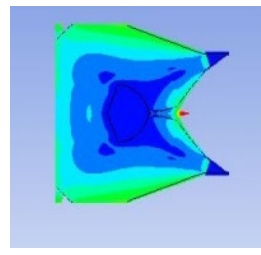

$\mathrm{T}=65 \mu \mathrm{s}$

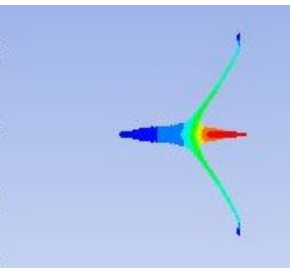

$\mathrm{T}=89 \mu \mathrm{s}$

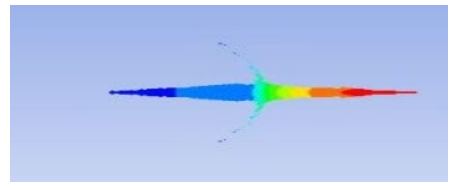

$\mathrm{T}=161 \mu \mathrm{s}$

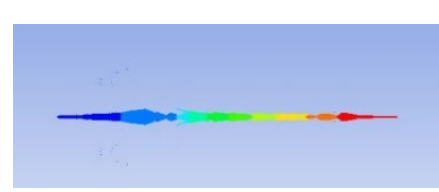

$\mathrm{T}=293 \mu \mathrm{s}$

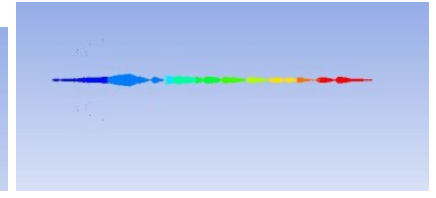

$\mathrm{T}=350 \mu \mathrm{s}$

Fig. 6 Formation of jet with wave shaper at different time steps

Fig. 5 and Fig.6 shows jet formation at different time steps without and with wave shaper shaped charge warheads.

Table- 2 Comparison of different parameters between without and with wave shaper SC warheads

\begin{tabular}{|l|c|c|}
\hline Parameters & $\begin{array}{c}\text { Without wave shaper SC } \\
\text { warhead }\end{array}$ & $\begin{array}{c}\text { With wave shaper SC } \\
\text { warhead }\end{array}$ \\
\hline Length of Jet(L)(in mm) & 1490 & 1644 \\
\hline $\begin{array}{l}\text { Jet-tip velocity }(\mathrm{Vj}- \\
\text { tip)(in km/s) }\end{array}$ & 6.08 & 8.14 \\
\hline Slug Velocity( in km/s) & 1.05 & 1.22 \\
\hline
\end{tabular}




\section{(B) Effect of liner Geometry in large caliber shaped charge warhead:}

Large caliber shaped charge warheads have been designed with conical as well as tulip shaped liner. Numerical simulations were carried out using AUTODYN software.Fig.7 and Fig.8 shows the formation of jet from conical and tulip lined shaped charge warheads at different times. Jet tip velocity was found to be $8.5 \mathrm{~km} / \mathrm{s}$ in conical shaped charge liner. The jet formed from shaped charge with tulip liner configuration has jet tip velocity of $6.0 \mathrm{~km} / \mathrm{s}$.

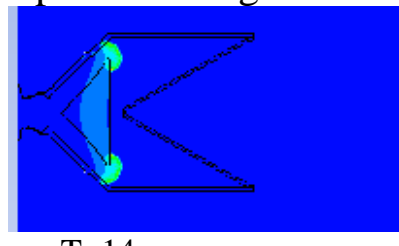

$\mathrm{T}=14 \mu \mathrm{s}$

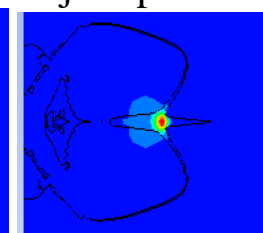

$\mathrm{T}=27 \mu \mathrm{s}$

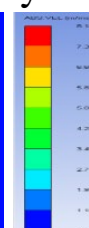

$\mathrm{T}=190 \mu \mathrm{s}$
Jet tip-velocity: $8.5 \mathrm{~km} / \mathrm{s}$

Fig. 7 Conical shaped lined shaped charge warhead
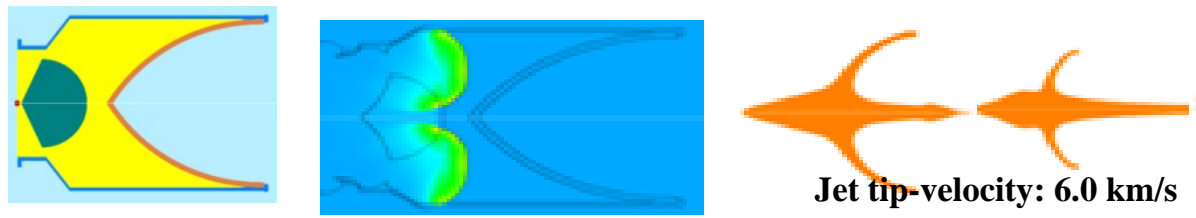

Fig. 8 Formation of Jet-tip velocity from Tulip shaped charge warhead

\section{(C) Effect of Liner Thickness in large caliber shaped charge warhead:}

Numerical simulations were carried out using AUTODYN software to study the effect of liner thickness for large caliber shaped charge warhead. Table- 3 shows the values of jet -tip velocity and slug velocity for different thicknesses with a constant liner cone angle of $60^{\circ}$. A nylon wave shaped was also used during simulations.

Table -3 Different Liner Thickness vs. Jet-tip velocity for constant cone angle $60^{\circ}$

\begin{tabular}{|c|c|c|c|}
\hline S.No. & Liner Thickness & Jet -Tip velocity $\mathbf{( k m} / \mathbf{s})$ & Slug Velocity (km/s) \\
\hline 1. & $4 \mathrm{~mm}$ & 8.14 & 1.06 \\
\hline 2. & $6 \mathrm{~mm}$ & 7.60 & 0.785 \\
\hline 3. & $8 \mathrm{~mm}$ & 7.19 & 0.671 \\
\hline 4. & $10 \mathrm{~mm}$ & 6.95 & 0.522 \\
\hline 5. & $12 \mathrm{~mm}$ & 6.70 & 0.517 \\
\hline
\end{tabular}

(D) Effect of liner cone angle:

2D simulations were carried out to study the effect of liner cone angle for constant liner thickness $4 \mathrm{~mm}$. Table- 4 shows the values of jet -tip velocity and slug velocity at different liner cone angles.

Table -4 Different Liner cone angle vs. Jet-tip velocity for constant liner thickness 4mm

\begin{tabular}{|c|c|c|c|}
\hline S.No. & Liner cone angle & Jet -Tip velocity $\mathbf{( k m} / \mathbf{s})$ & Slug Velocity (km/s) \\
\hline 1. & $50^{0}$ & 8.55 & 1.80 \\
\hline 2. & $60^{0}$ & 8.14 & 1.06 \\
\hline 3. & $70^{0}$ & 7.63 & 1.34 \\
\hline 4. & $80^{0}$ & 7.58 & 1.53 \\
\hline
\end{tabular}




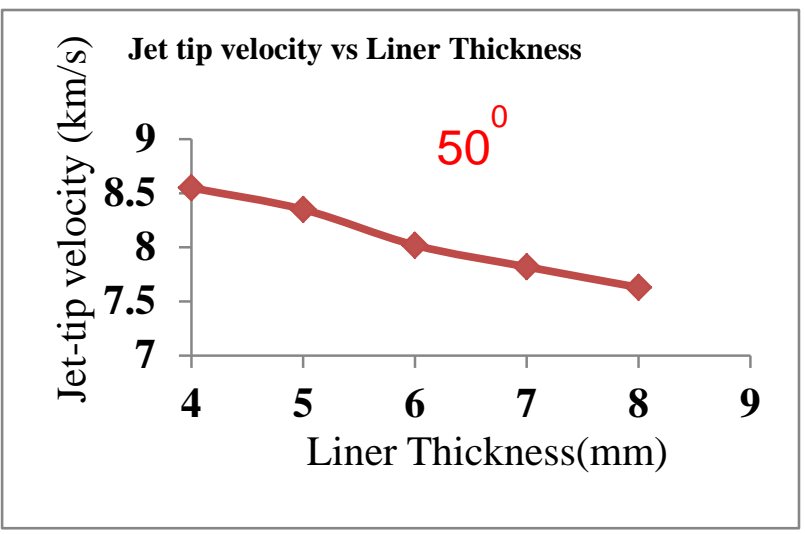

Fig. 9 Jet tip velocity vs. liner thickness for cone angle $50^{\circ}$

\section{Jet tip Velocity vs Liner thickness}

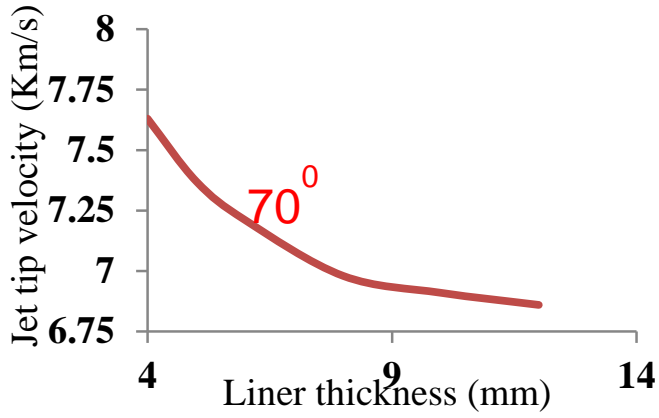

Fig. 11 Jet tip velocity vs. liner thickness for cone angle $70^{\circ}$

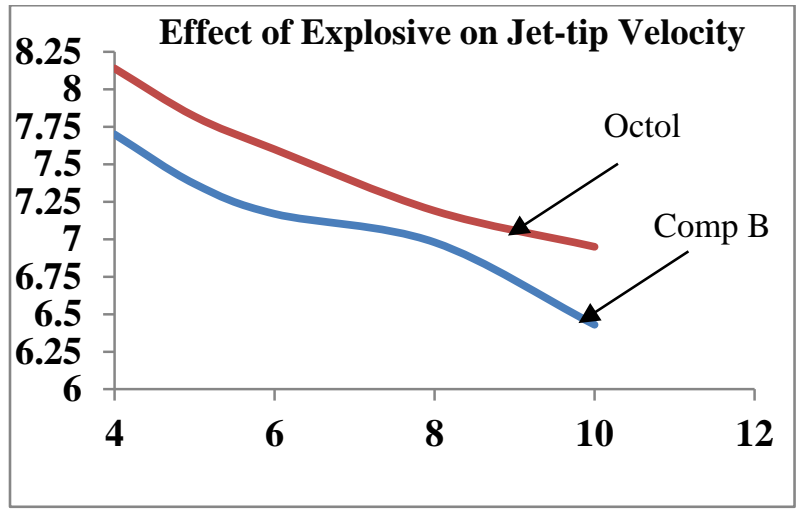

Fig.13 Effect of Explosive

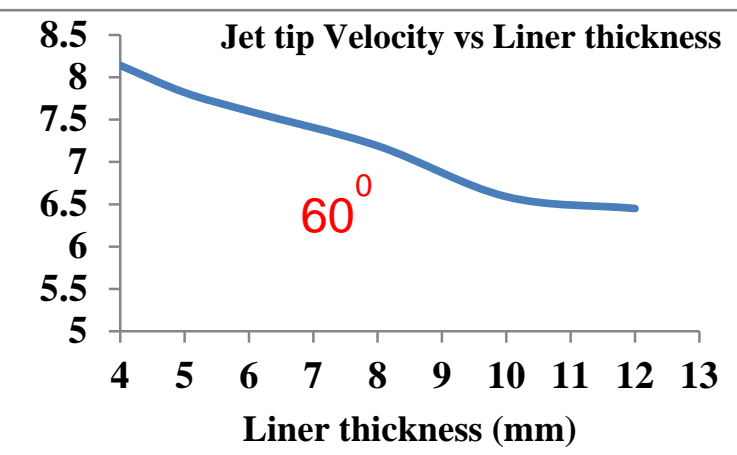

Fig. 10 Jet tip velocity vs. liner thickness for cone angle $60^{\circ}$

Jet tip- velocity vs liner thickness

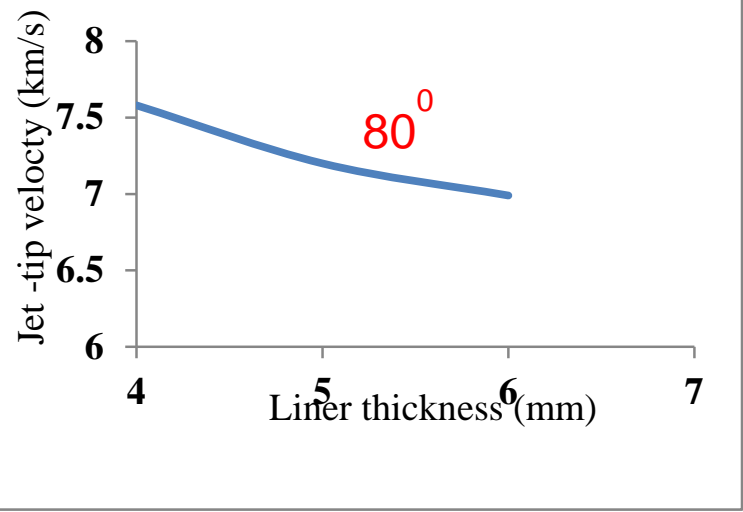

Fig. 12 Jet tip velocity vs. liner thickness for cone angle $80^{\circ}$

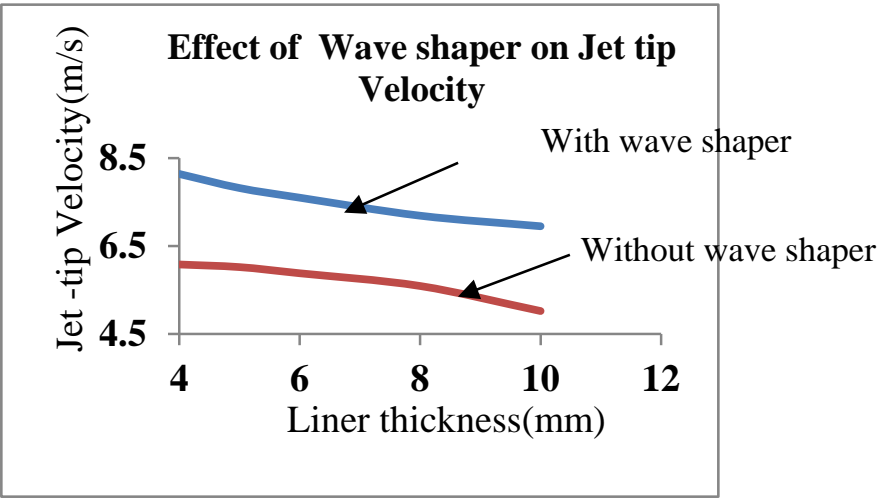

Fig.14 Jet tip velocity vs. liner thickness for cone angle $60^{\circ}$

\section{Results and discussions}

Table-1, 2, 3 and 4 show the results obtained from AUTODYN-2D numerical software. From simulations, it has been observed that jet-tip velocity is $6.08 \mathrm{~km} / \mathrm{s}$ without wave shaper based shaped charge warhead whereas it was $8.14 \mathrm{~km} / \mathrm{s}$ in case of with wave shaper warhead. Jet length is also $1490 \mathrm{~mm}$ in case of without wave shaper warhead whereas it was $1644 \mathrm{~mm}$ in case of with wave shaper based shaped charge warhead. It has been observed that in case of wave shaper warhead there is more than 15\% increase in jet tip velocity and 10\% increase in jet length in comparison to without wave shaper warhead due to increase in collapse velocity of liner elements. Jet tip-velocity is more in case of conical shaped charge liner in comparison to tulip shaped charge liner geometry 
but jet diameter is more in tulip liner geometry. The numerical simulation results showed that the jet tip velocity decreases in between $15-20 \%$ of liner position with increasing the cone angle when the other parameters are the same. In the simulations performed for different cone angles $50^{\circ}, 60^{\circ}, 70^{\circ}, 80^{\circ}$ it is observed that as an increase of cone angles, the jet-tip velocity decreases and slug velocity increases. In addition, as an increase of cone angle, the forward jet-tip diameter increases. For the constant cone angle $60^{\circ}$, jet tip-velocity decreases as liner thickness is increased from $4 \mathrm{~mm}\left(\mathrm{~V}_{\text {jtip }}: 8.14 \mathrm{~km} / \mathrm{s}\right)$ to $12 \mathrm{~mm}\left(\mathrm{~V}_{\text {jtip }}: 6.70 \mathrm{~km} / \mathrm{s}\right)$.It was also observed from simulations that jet-tip velocity was increased in between $8-10 \%$ when Octol was chosen in place of CompB as explosive.

\section{Conclusion}

The purpose of this study is to perform an optimum modelling on order to benefit the shaped charge in an effective manner. Validations of these codes have been done only by matching the experimental results of the shaped charge warheads. There is an appreciable increase in jet-tip velocity and jet length in case of wave shaper shaped charge warhead thus there is an increase in penetration in the target. It can also be concluded that large caliber shaped charge performance are greatly influenced by the line geometry, liner thickness, liner cone angle, explosive and wave shaper and a decision for the selection of liner geometry and dimensions of shaped charge penetrator should be done according to target, required desired effect on target, permissible weight and available space for the warhead.

\section{References}

1. W.P Walter, J.A Zukas “Fundamental of Shaped Charges” John Wiley Interscience Publication.

2. Theory Manual ANSYS AUTODYN

3. M.A Meyers, Dynamics Behavior of Materials, Wiley, New York, 1994

4. Mayseles M, Hirsch E, Lindenfeld A, "Effect of explosive in the shaped-charge jet formation characteristics”, $16^{\text {th }}$ Int. Symp. Ballistics, San-Francisco, USA, Sept. 23-28, 1996

5. J.F Molinari "Finite element simulation of shaped charges", Finite Elements in Analysis and Design, Vol.38, 2002, pp 381-389. https://doi.org/10.1016/s0168-874x(02)00085-9

6. I. Gokhan Aksoy, Sadri Sen "Effect of the variation of conical liner apex angle and explosive ignition point on shaped charge jet formation ”, Indian Journal of Engg. \& Material Sciences, Vol.10, Oct.2003, pp 381-389

7. Chen CY et al. "Design of an inert material type plane wave generator" Propellants Explosive, Pyro techniques, Vol.18, 1993, pp 139-145. https://doi.org/10.1002/prep.19930180305

8. G. Pezzica et al "Calculation of the wave -shaper effects on Detonation wave in shaped charges" Propellants, Explosive, Pyrotechnics, Vol. 12, 1987, pp 125-129. https://doi.org/10.1002/prep.19930180305 